\title{
Racing against Time? Aspects of the Temporal Organization of the Runner's World
}

\author{
Greg Smith \\ University of Salford
}

\begin{abstract}
Drawing on documentary sources and participant observation, I seek to specify salient temporal characteristics of the social world of running. Extant analyses seem preoccupied with criticizing running temporality for reproducing, in a sporting context, those Taylorized, alienating beliefs and oppressive practices typical of capitalist sites of production. A different point of departure, runners' own understandings, shows that temporal considerations are a key constituent of the runner's self that is not experienced as alienated. Three aspects of running temporality are highlighted: the large-scale temporal organization of the running world, with a focus on the cyclical racing pattern and the planned and scheduled character of training; temporal features of running careers; and the way in which "times" figure in the activity of running and its description. I conclude that these temporal organizations are important symbolic resources that help to build and reaffirm the runner's self. Rather than time alienating and exploiting runners, runners exploit it as a constructive resource that they can deploy in diverse ways.
\end{abstract}

The temporal dimension is a conspicuous feature of the talk and activity of runners at every level of ability and involvement. Close students of running and runners themselves take a keen interest in the "lap times," "personal bests," and "records" set for a multitude of combinations of gender and age grading, place, and event. Temporal indications are also prominent in speech about activities related to the enactment of running. One often hears talk of "finding the time" for training, of "training schedules," of "good days," of "weeks missed" (because of illness, injury, etc.), of "next year's aims," of "recovery periods," of "weekly mileages," and so on. Time, that omnipresent characteristic of social life, has special significance in the running world. Runners learn to attend to time as finely tuned markers of running achievement, as careers with stages and turning points, and as cyclical calendars.

This article addresses selected aspects of the significance of time in running through a qualitative study of published accounts given by runners ${ }^{1}$ about their ac-

Direct all correspondence to Greg Smith, Institute for Social Research, University of Salford, Salford, Greater Manchester, M5 4WT, United Kingdom; e-mail: g.w.h.smith@salford.ac.uk.

Symbolic Interaction, Volume 25, Number 3, pages 343-362, ISSN 0195-6086; online ISSN $1533-8665$. (C) 2002 by the Society for the Study of Symbolic Interaction. All rights reserved.

Send requests for permission to reprint to: Rights and Permissions, University of California Press, Journals Division, 2000 Center St., Ste. 303, Berkeley, CA 94704-1223. 
tivities. These accounts appeared in a leading British magazine about athletics; I supplemented my analysis with data from participant observation. Most of the material presented here necessarily deals with the reported experiences of elite runners. My primary interest in this material is interpretive, that is, directed toward the sociological elucidation of participants' understandings of common temporal patterns.

\section{METHODS AND DATA}

The published accounts derive from two main sources: (1) approximately fifty interviews with accomplished runners published over a four-year period in a popular British athletics magazine; (2) forty replies to a standard questionnaire distributed by the same magazine and published as an occasional column, "Who's Who in British Athletics." For convenience, I refer to these two sources of data as "interview profiles" and "questionnaire profiles" respectively. I have also used selected excerpts from newspaper and other magazine reports and kindred biographical sources. These documentary sources of data are supplemented and contextualized by field notes from several decades of my own participation in and observation of running. Although the participant observational data added to the documentary data and provided new information, I maintained a reflexive relationship between both data sources. Inspection of the documentary sources has helped to make my taken-forgranted understandings of the running world more explicit. At the same time, my direct knowledge of running and runners' typical experiences aided the interpretation of the documentary materials.

Both the interview profiles and the questionnaire profiles invite the runner to reflect on his or her experiences, but the former does so in a more unstructured way. The interviewer is a staff journalist who specializes in covering running events. We cannot regard published interviews as literal representations of the interviewersubject encounter-some "working up" of questions and replies probably occurs in the majority if not all of the cases-but this need not invalidate the material for sociological purposes. Unlike the interviews, the list of questions put to the subjects of the questionnaire profiles was not published but can be inferred ${ }^{2}$ readily from the answers reported. The subjects were asked to provide personal details and a range of factual information and opinions about his or her running career. (See Appendix A.)

In drawing on these data for analysis, I used an archival procedure to yield an "unobtrusive measure" (Webb et al. 1966) of the temporality indigenous to running. The fundamental methodological assumption turns on the researcher's interest in the runner's point of view, in how runners plan, schedule, organize, and describe their activities. Consequently, the natural material to attend to is runners' talk about their sport. A sample of such talk is readily available in my main sources, magazine and newspaper articles, as well as television and radio reports, autobiographies, and the like. ${ }^{3}$ These sources provide a rich fund of relevant material for interpretive analysis. Such data have the advantage of "nonreactivity," for they are accepted as part of the runner's world that they describe. For some purposes, this 
material might be regarded as unrepresentative and biased. However, for qualitative analysis, a different valuation can be made, as this material gives us information about those who lie at the very center, rather than the periphery, of the running world. Moreover, because my interest here lies in the analytic description of timerelated practices and not with the incidence or prevalence of these practices among runners, the charge of bias in its usual form does not apply.

\section{TIME IN CRITICAL THEORIES OF SPORT}

In the extant sociological literature on sport, temporal organization figures most prominently in commentaries emanating from critical theory. For present purposes, "critical theory" can be used to group those writings (not necessarily all inspired by Marx or critical theory) that detect something unnatural and perhaps pernicious in the runner's orientation to the stopwatch and her or his constant pursuit of records. These theories present such temporal features as symptomatic of the shaping or determination of running beliefs and practices by larger social formations. Although the most systematic critical theories emanate from the Left (Rigauer 2000), we can also find kindred criticism from other ideological fields. ${ }^{4}$ For example, the conservative journalist Patrick Marnham (1980:25-26) points to the "corrupting" influences of digital technology. He maintains that the race has its own "natural drama" and that the introduction of "split second timing" is quite simply a "meaningless addition." Marnham objects to the way records have come to be seen as the be-all and end-all of competition, so much so that media commentary increasingly focuses on "the mechanical event, differentiated from other such events by hundredths of a second." The real significance in competition, he suggests, lies in the interplay of individual characters. And this mechanical stance is thoroughly conducive to the purposes of "totalitarianism," a system that is unable to cope with individual difference. In this view, the digital clock is the very enemy of spontaneity and individuality, representing a "totalitarianism that is creeping through the Western world."

Less charged critical views include those of the cultural theorist Fred Inglis (1977) who sees a "grim heroism" in the strivings of the distance runner. In measuring his or her efforts against the minute divisions of the stopwatch, the runner symbolizes the emphasis our culture places on achievement. Accordingly, "long distance running is the sporting triumph of the ethic of individualism" and can be regarded as "part of the puritan spirit and its awful exaltation of the stiff, insensate will" (Inglis 1977:43). Inglis does not see temporal technology as corrosive of the human spirit; rather he takes it to be an icon of the currently preferred shape of that spirit.

However, this assessment simply will not do as adequate analysis for Marxist approaches. In the eyes of the French Marxist Jean-Marie Brohm, sport is to be regarded, most generally, as "a colossal process of alienation" (1978:111), which arises from what he sees as "a structural parallel between the capitalist mode of production and the sporting process" (1978:69). In his theoretical statements Brohm invariably uses "sport" as a generic term, but clearly many of his assessments are 
shaded by his observations of track and field athletics (note the title of his book: Sport: A Prison of Measured Time). His basic point seems to be that activities such as running are nothing more than idealized reflections of the dominant forms of capitalist sociality: "The driving forces in sport-performance, competitiveness, records-are directly carried over from the driving forces of capitalism: productivity, the search for profit, rivalry and competitiveness" (1978:50).

Brohm also maintains that "sport is the institutionalized positivism of physical progress" (1978:69; emphasis removed). Sport measures human progress through constant improvement in records. Time is, of course, central to the measurement of records: "time in sport is a smooth descending curve." Human progress has been quantified into sporting performances that can be measured by the instrument of abstract time-the stopwatch. Sport thus generates its own mythology centered on a fundamentally "childish" question: who is best? A mythology of "fabulous exploits" is manufactured. Symbolic barriers are arbitrarily hewn from the relevant range of performance values (four-minute miles, ten-second 100 meters, etc.), values that then serve as markers for the periodization of sports history. The authors of these performances also assume mythic status; they become champion-supermen/women. All this concern with precise timing, systematic measurement, and the recognition of records is not, Brohm maintains, an eternal and universal feature of sport; rather it epitomizes modern competitive sport. Winning has been reified. A fetish is made of records. Marx's description of the modern labor process could well apply to the modern runner: "time is everything, man is nothing; he is, at most, time's carcase" (cited in Brohm 1978:74).

Bero Rigauer's (1981) work is a more precise development of Brohm's general critique. Rigauer explores the structural similarities of sporting activity and the work activity of the wage laborer, whereas Brohm asserts a broad homology between capitalism and modern sport as the touchstone of his analyses. Rigauer's major claim has particular relevance to the temporal aspects of running. He argues that the toplevel runner is a specialist whose record-breaking performances represent essentially collective, not individual, achievements. These performances depend on collaborative relationships between the runner and other specialists (coaches; experts in sports physiology and medicine; promoters; etc.). A division of labor characteristic of capitalist work relations is thus evident. Interval training methods represent a "Taylorization" of sporting activity comparable to assembly line production techniques (Rigauer 1981:33-40). Just as the wage laborer's workday is carefully planned as a period of productive activity, so too the runner's weeks and years are planned in accordance with training programs that "clearly show the traces of rationalized, goal-oriented, planned behaviour" (1981:44). For Rigauer the runner's times express the quantitative consciousness that reduces the individual human to an abstract commodity, "the 9.9-second-man" $(1981: 58,71)$, just as the wage laborer produces commodities valued only in exchange terms (see also Peters 1976).

The critical theories outlined above suggest connections that might be forged between the present study and established varieties of social criticism. Rigauer (1981:107- 
11) rightly insists that we should not privilege sport as a form of social activity and absolve it from critical scrutiny. The critiques also serve as reminders of how running, like any other contemporary sport, bears the imprint of aspects of the Western, modern industrial society that sustains it: sport involves social relations not entirely divorced from the environing society. ${ }^{5}$ I do not intend to refute the critiques outlined above but to indicate the partial nature of their analyses and thereby suggest that the temporality of running consists of much more than they envision when we understand running from the point of view of those who participate in it.

\section{THE RHYTHMS OF THE RUNNING WORLD}

The temporal organization of the running world has a fundamentally cyclical structure. Competitive events-races-lie at the heart of this temporal organization. Races are the red-letter days on runners' calendars, and runners direct their efforts toward doing well in them. Although races take place year-round, particular kinds of races typically occur at certain times of the year: in Britain the major division is between a cross-country season, extending approximately from October through to March, and a "track" season, occupying the intervening summer months. Little track racing is done outdoors in winter; cross-country races are rare in the summer months (there are, of course, exceptions to the rule). Climate obviously plays an important part in determining this division: cold, wet weather seldom promotes fast track running, but it creates the abundance of mud essential to genuine cross-country racing. Road racing is the one type of competition that takes place on a year-round basis, and many runners, especially older ones, race only on roads. A seasonal pattern is evident: in Britain few marathons take place in the coldest and darkest winter months, while short road races (of 1 mile and 5 kilometers) are usually held in the spring and summer, often in the light evenings.

Climate determines in broad outline the temporal scheduling of races opportunities. Its influence is pervasive and quite fundamental. Indeed, what we seem to have is an example, in a modern industrial society, of E. E. Evans-Pritchard's (1939, 1940) notion of "oecological time"- a notion originally devised to describe those cyclical concepts of time that were considered reflections of the Nuer's relations to their environment.

However, runners differ from the Nuer of Evans-Pritchard's day in that, along with most other members of Western society, they orient to a "standard temporal reference framework" (Zerubavel 1977) in which they measure the passage of time according to the conventional units days, months, years, and so on. In addition, however, runners impose a series of calibrations of their own on this standard framework. Many races occur at fixed times of the year. For example, the English National Cross-Country Championship is usually held on the first Saturday in March each year. At any point in the year, the competitive runner can situate his or her present in terms of immediate past and future races. A temporally ordered program of races, a program institutionalized as a "fixture list," is known in advance and func- 
tions as a kind of map for the runner, providing a relevant set of benchmarks. Marvin Scott, in his book on horse racing, reports a similar practice among grooms at racetrack stables:

Time is measured not by the calendar but by the racing season. The past is punctuated by the emergence of a series of great horses, and the benchmarks of the passing of time are referred to as "the year of Whirlaway," "the year of Citation" and so forth. For backstage people, everyone has the same big clock. (1968:72)

Distance runners will sometimes speak of "the year Bernie Ford won the National" (the English Cross-Country Championships). Of course, the fixture list itself is one type of calendar, and as such it has those properties that Durkheim (1915:11) identified long ago: "a calendar expresses the rhythm of the collective activities, while at the same time its function is to assure their regularity" (see also Zerubavel 1981:70-100).

Most races held on a recurrent basis, championship races especially, are annual affairs. That a particular race takes place only once a year no doubt imposes a certain urgency on the individual's performance and serves to heighten interest in its outcome. Many races at the international level, however, occur at longer intervals, sometimes as long as four years. The four-yearly Olympic cycle currently constitutes the master cycle in running, and winning an Olympic gold medal is still the supreme accolade any runner can receive (although the introduction in 1983 of the World Athletics Championships, now held every two years, represents a significant challenge to the importance of the Olympics). The European Athletic Championships are also held every four years, and comparable competitions exist on other continents (the Pan-American Games, the Pan-Africa Games, the Asian Games). We can distinguish, then, the broad picture of an annual cycle of races up to the national level overlaid by the longer cycles of Olympic Games and World Championships at the international level.

The training of the competitive runner is organized to mesh with these cyclical patterns. In terms of time and effort expended, training constitutes the larger part of running activity; typically, races are the "ends" to which training is the "means." Training involves the cultivation of one's athletic abilities, and it must be undertaken systematically if the runner is to reap a satisfactory reward, whether in competitive performance or personal well-being. There is much debate over the relative merits of different methods of training; also, individual training varies a good deal. Not surprisingly, then, a sizable proportion of each questionnaire profile is devoted to the runner's training. Although the responses to the questionnaires vary markedly, the questions are standardized and reveal a widely taken-for-granted temporal pattern of training (see Appendix A). From an inspection of these questions we can conclude that for most runners the week is the basic training cycle. Training usually takes place on a given number of days each week, and a similar type of training tends to be performed on the same day each week (e.g., circuit training on Tuesdays, hill running on Wednesdays, etc.). Races typically take place on weekends, and the 
longest and most time-consuming run occurs on Sundays. Given that most runners in Britain also have jobs, the temporal organization of training into a weekly cycle probably responds, in the first instance, to constraints exterior to running. For the runner in paid employment, Saturdays and Sundays allow the maximum amount of time to devote to this leisure activity. ${ }^{6}$ Although some runners operate with longer cycles for certain types of training-for example, fortnightly weight training schedulesthe week is clearly the basic unit of the training cycle.

The interview profiles also yield information about standard seasonal variations in the weekly cycle. Obviously, the type of training undertaken in a given week must be coordinated with the type of race the runner wishes to attempt. Runners modify training schedules according to season and also according to the anticipated race. Track runners' widely adopted pattern (as the questionnaire profiles show) treats early fall as a fallow period, builds up the weekly mileage to a maximum around January or February, and then drops the mileage slightly and increases the intensity (this involves what is sometimes known as "speed endurance training"). Finally, as the warmer weather arrives in spring, track runners undertake some "interval training," that is, training involving short fast runs, with measured recovery periods. Their typical pattern maximizes racing performances in the summer.

Interestingly, elite runners reproduce precise details of their training for publication. They have a sure grasp of what training they did and when they did it. As noted above, effective training has to be systematic. This systematic approach entails keeping what runners call a "training diary." By means of this precise record, the runner can refer accurately to training completed one or more years ago and plan intelligently for the future. By reference to the training diary, the runner can engage in a retrospective search for reasons for particular racing performances, illnesses, injuries, and so forth.

I have described two leading features of the temporal organization of running as the cyclical racing pattern and the planned and scheduled character of training. A basic problem for runners is coordinating these features, that is, to have done adequate training in preparation for valued races. Training for a race resembles preparing for an examination, and the racer's anxieties in many ways parallel those of the student. We could suggest that the likely psychological consequence of these temporal organizations produces strong "future time orientations," that is, a well-developed capacity to link images of the future with concepts of the past and present (Cottle and Klineberg 1974). As a social type, the runner could be seen as the antithesis of Finestone's ([1957] 1964:288) "cat," whose general orientation is fatalistic, who eschews future planning, who lives for today, and who prizes "kicks" above all else. We might also propose that attending to the temporal features outlined in this section offers a sociological avenue of investigation into the phenomenon of "running addiction." An alternative sociological explanation counters those based on personality (e.g., Crossman, Jamieson, and Henderson 1987; Diekhoff 1984; Hinkle, Lyons, and Burke 1989; Morgan 1979) that have become established in the literature. ${ }^{7}$ 


\section{MAPPING THE RUNNER'S CAREER}

Elite runners judge their running biography in "career" terms-an eminently temporal notion and one that forms the major focus of the interview and questionnaire profiles. How are careers conventionally described in these data? The runner's career typically emphasizes chosen events and outstanding performances and accomplishments. Thus an athlete is usually described as a "1500 meters runner" but also as a "3:40 performer." A "time" displays an athletic capacity, yet, as a type of credential, it also bestows a particular identity: it is emblematic of a self. Small wonder, then, that runners speak of these emblems in possessive terms such as "my 2:08," "my 13:20," and so on. When runners trace their best times for a given event over a period of years, they create a table known as an "annual progression." We can readily gain an impression of a runner's career simply by glancing at such tables. Accomplishments, that is, placings in major races and championships, also serve as benchmarks in the runner's career (and these too are faithfully listed in the questionnaire profiles).

In reading an annual progression table, we make sense of a runner's career by means of the "documentary method of interpretation." Harold Garfinkel (1956:194) wrote: "The documentary method is a way of realizing the unity of a biography. The work of historicizing past events, either for a particular person or a collectivity, consists of the application of the documentary method to the task of selecting and ordering past occurrences." The "past occurrences" selected and collected by the annual progression table are the runner's best times for an event for each year, arranged in successive order. These times consist of the "actual appearances" assumed to "point to" an "underlying pattern," namely, the varying fortunes of a runner's career. But we can only make sense of this collection of times as an annual progression table by means of some "presupposition" of the careerlike structure of participation in running. However, the annual progression table is schematic and designed as no more than a rough index of a runner's career. Sometimes it will be revealing, sometimes misleading. Obviously, we can appraise a year's races in other terms than best performance-for example, individuals beaten, consistency of performance, placings in significant races-and these criteria figure in certain of the more sophisticated ranking lists assembled for the major championship distances.

The notion of career is indigenous to the culture of competitive running (and doubtless more generally to Western sports). However, instead of regarding the concept as a simple extension of the language and logic of capitalist labor to an ostensibly playful sphere (as do critical theorists), it seems more cogent to approach running careers from the point of view of George Herbert Mead's (1932) theory of time. For Mead the past is not a simple accumulation and sedimentation of presents. Social actors always select their pasts from the vantage of a present (Mead 1932:79,16-18). The questionnaire profiles accentuate this temporal process, objectifying the runner's responses made in a present through their publication in a specialist magazine. The process of selecting a past can be seen, above all, in the question "When did you first realize you could reach international level?" which requests the 
respondent to answer in terms of a discrete "turning point" (Hughes 1958; Strauss [1959] 1977). Runners commonly reply to this question by identifying a critical race that they see in retrospect as a "testing point" (Roth 1963:84). Testing points have a make or break character; they are critical turning points in determining the career direction a runner will take. One runner who realized that she could reach international level gave a typical reply: "In 1973 when beating Joan Allison and Margaret Coomber in the Kent County 800 championship in a personal best of 2:09.5-an improvement of six seconds" (Athletics Weekly, May 8, 1976). For some runners, such realizations come suddenly and unexpectedly. In one classic case, a hitherto undistinguished runner had the revelation that he could reach the international standard "at about 3:00 P.M. of October 27th, 1973" (Athletics Weekly, May 30,1980), shortly before completing and winning the very first marathon he attempted (he went on to win the Commonwealth and European titles the next year).

Careers in running can begin at about the age of ten or eleven. A wide range of age-graded competitions are available to ten- to twenty-year-old athletes. Between twenty and forty the athlete has "senior" status; runners deem this period the most propitious for performance. Career lines need not end at forty; a great expansion in "Veterans" ("Masters" in the United States) running has occurred in recent years, which is age graded in five-year bands. Thus organized running provides for the commencement of a career line at almost any age. This fact has led one ethnographer to argue that the critical differences between runners should be identified not in age terms but in terms of "moral career": changes in diet, physical appearance, outlook, shoes and kit worn that are seen to herald and index changes in selfconception (Nash 1976).

As in all careers, runners have ups and downs; some have Indian summers. All runners must accommodate the finitude of their sporting careers, just as we must all face the finitude of our lives. Participation in sport, perhaps more than participation in many other activities, forcefully reminds us of these natural limitations. Peter L. Berger and Thomas Luckmann put it this way:

My own life is an episode in standard time. This time was here before me and will go on after me. The knowledge of my inevitable death makes this time finite for me. I have only a certain amount of time available for the realization of my projects, and the knowledge of this affects my attitude to these projects. Also, since I do not want to die, this knowledge injects an underlying anxiety into my projects. Thus I cannot endlessly repeat my participation in sports events. I know I am getting older. It may even be that this is the last occasion on which I have the chance to participate. (1966:41, emphasis added; see also Schutz and Luckmann, 1974:47-48)

Runners evince more mundane versions of these ideas in their reasoning. An international middle-distance runner was once reported as saying, "I'll race anyone, because you never know-you may not be running in a couple of weeks' time" (The Guardian, July 19,1977), echoing the frequently expressed opinion that every wellknown runner is just one injury or illness away from obscurity. 


\section{A GRAMMAR OF "TIMES"}

As should now be apparent, runners and all those who take a close interest in running have an abiding concern with "times." Times confer a particular and precise identity on a runner. Thus in the specialist press one often reads headlines such as "Boit 2'15"13, Ovett 7'41"3 (L'Equipe, September 26, 1977); “Tatyana Kazankina3:52.5!" (Athletic Weekly, August 23,1980). Times can work as a method for rendering running performances accountable, that is, objective, describable, and recognizable for what they are. To say "I ran a two-mile race only a few weeks ago in 9:35" (Athletics Weekly, May 19,1980) makes a description of a particular athletic performance publicly available. The "time" measures an instance of running as a fixed duration, as abstract and objectively identical units of time. How, then, is it possible to speak (as runners do) of "fast times" and "slow times"? After all, any runner cannot move faster or slower than another in the flow of time, when we have only one uniform measure of time. The philosopher John Wild formulates the problem in the following way:

One runner in a race may arrive at the spatial end point sooner than another at 2:05. But he cannot reach the instant 2:05 sooner than another. If this were possible, sooner than would lose all meaning, for there would be no constant measure. $(1954: 543)$

Any analysis of "times" must address what William J. Morgan (1978:145) has called "the ineluctable spatialization of time." In the first instance, "times" are always relative to the distance covered and to the mode of traversing that distance (whether it be running, race walking, hurdling, steeplechasing). This feature of "times" alerts us to a characteristic of running diametrically opposed to the form of life immortalized by Rudyard Kipling (quoted in Opie and Opie 1973:324) in his poem, "If": "If you can fill the unforgiving minute/With sixty seconds' worth of distance run."

What matters in most cases is the time taken to cover a specified distance, not the distance covered in a fixed time. Some relatively uncommon exceptions to this generalization are evident, such as one hour and twenty-four-hour races in which the aim is to cover the maximum possible distance in those time periods, but by and large the time-distance ratio predominates in making a runner's performance accountable.

I have argued that "times" make performances in running races accountable. We can state this observation as an interpretive rule for runners: If it is possible to describe a performance in terms of a "time," then so describe it. I next explore some of the conditions and associated forms of reasoning in which such a rule has diminished significance or no real relevance at all for runners. It is plainly the case that running performances are also accountable in terms other than those of "times."

A condition for the adequacy of times as measures of performance is that the race actually is its stated distance. In track racing distances are readily calculable because outdoor tracks have standard dimensions: they are 400 meters long, the straights have a specified length, and the bends have a determinate curve (indoor 
tracks tend to be rather less standardized). This standardization enables unequivocal comparisons to be made, say, between a 5,000-meter performance on a track in Prague with a 5,000-meter run on a track in Dublin. Races up to 400 meters are run entirely in lanes to eliminate the possibility of fast-moving competitors colliding with one another. This practice, however, introduces a source of variability in that runners in the outer lanes in races that involve running at least one bend cannot see their fellow competitors for part of the race. These runners have been placed farther forward in space than competitors on the inner lanes (this practice ensures that everyone runs exactly the same distance). Thus the true situation in the race becomes apparent only "when the stagger unwinds." For this reason many runners prefer to run the inner lanes because it reduces the period in which they cannot see the other competitors. In televised sports, commentators are usually quick to note the disadvantage faced by the runner in the outside lane and runners themselves express sentiments such as feeling "choked" (Athletics Weekly, January 22,1977).

This same logic also dominates in the longer events that do not have lanes. The most favorable position is that closest to the curb where the distance for one circuit of the track is exactly 400 meters. The curvature of the track forces some runners to "run wide" in the second and third lanes. They end up running farther than those closer to the inside, which can lead athletes to revise their judgment of a time. For example: "I went through the first lap in 50 and bits. I probably lost seven or eight meters (through being pushed into an outer lane), so it was probably worth 49" (Athletics Weekly, January 22, 1977). This athlete reasons that "50 and bits" for approximately 408 meters translates into " 49 " seconds for 400 meters.

Distance races, of course, take place on surfaces other than the track: cross-country running and especially road racing are immensely popular in Britain. Runners pay less attention to times on such surfaces, in large part because they present variable racing conditions: some courses are hilly, others flat; some courses present obstacles (streams, fences), others do not; some courses consist of "laps," others are of the "out and back" variety. All these conditions can affect a runner's time, and they can affect some runners more than others. Thus a leading track athlete tells us, "I am not a very good cross-country runner ... [I]f it [the course] is flat I can run on it, but if it is mud and hills then I just don't want to know" (Athletics Weekly, December 24, 1979).

Road and country times assume lesser significance because of the enormous variety of courses, as the general absence of split-second timing indicates. Runners, however, keep "course records" that stand as benchmarks against which they can judge race times. Therefore, runners regard cross-country racing differently than other types of races. Placing in the field assumes more importance than the time. Indeed, British runners sometimes voice complaints when courses do not seem to meet the standard features of cross-country-ditches, plowed fields, and mud. Many cross-country races in continental Europe are held on the smoother surfaces of race courses, but British runners sometimes feel that these surfaces are too closely akin to track racing. They often judge road courses a little differently. 
Although their length is usually carefully calculated with a measuring wheel, runners are prone to question the veracity of the stated length of the course. The remark of a former world record holder for the marathon is typical:

Well, that 2:09:36-I never knew I could run that fast. Matter of fact, that was one instance where I thought there was something wrong with the course or timing. . . . I couldn't believe it when they said 2:09:36. I thought, hell, 2:19:36 it should be. I thought maybe they left the "one" off. (Athletics Weekly, April 19, $1980)^{8}$

Similar reasoning is common when competitors clock a series of "fast" times. In these cases it is believed that the course is short. The usual argument is, We know what times athletes $\mathrm{X}, \mathrm{Y}$, and $\mathrm{Z}$ are routinely capable of for the distance, yet in this race isn't it odd that $\mathrm{X}, \mathrm{Y}$, and $\mathrm{Z}$ are running a good deal faster? The course "must be" short. A fast time for a road course but especially a series of fast times can give rise to doubt about their "authenticity."

Unfavorable or excessively favorable climatic conditions-for example, when the temperature, humidity, or atmospheric pressure falls outside the "normal" range, or when there is excessive wind of rain-can also serve as grounds for questioning the adequacy of times as performance descriptors. A runner who set a British record for the mile on a cold Norwegian evening gave some idea of what "normal" weather conditions mean. This runner was reported as saying, "I never thought I'd see my own breath during a track race in summer" (Athletics Weekly, November 2, 1977). A race report provides another example: "The freak warm weather that sent the barometer [sic] up to $70^{\circ} \mathrm{F}$ made times relatively slow throughout, with several class men unable to break 50 minutes" (Athletics Weekly, May 3, 1980).

Under international rules, times recorded for the short sprints and hurdle races that show evidence of a following wind in excess of two meters per second must bear the suffix $w$, thus $10.12 \mathrm{w}$. Although there is not yet formal control of times under certain atmospheric pressures, informally runners distinguish between times recorded near sea-level altitudes and those recorded "at altitude" (usually 5,000 to 10,000 feet above sea level). It is no coincidence that world records for men's short sprints and long jumps have been set at altitudes where air resistance is lower. Altitude has a detrimental effect on distance performances.

Ranges of ways in which times, on their own, are unsatisfactory descriptors of performance have been examined. However, I do not suggest that in such circumstances times are "poor" or "inadequate" or "unreliable" descriptors per se. Rather, what I have outlined includes some of the common factors that runners may employ in conjunction with times to appraise a performance. I also want to draw attention to the different ways of attending to times according to their use. Let us look again at the weather example: "The freak warm weather that sent the barometer up to $70^{\circ} \mathrm{F}$ made times relatively slow throughout, with several class men unable to break 50 minutes." Here a race report reflexively ties "times" to "weather conditions," such that the evaluation of each requires an assessment of the other. (Why 
were the times so slow? Look at the weather. How bad was the weather? Just look at the times.)

An interest in how runners attend to times according to their use leads us into an area of explanations, excuses, and justifications occupied by the sociology of motivation (e.g., Goffman 1971; Lyman and Scott 1968; Mills 1940; Nash 1980). More work might be done on these materials from this perspective; here I want to consider a few illustrations to suggest certain possibilities.

A strict time-based judgment of a runner's performance will sometimes be undercut by citing such extenuating circumstances as recovery from illness and injury, lack of effort, or evidence of "proper" preparation. When a road course record formerly held by Brendan Foster was broken, a colleague of his defensively pointed out, "Bren's record's not much anyway-he did it off 130 miles that week" (Athletics Weekly, May 3,1980). This statement asks us to believe that Foster's old record was not as good as it might have been because before the race Foster was tired from running a very high training mileage (and as a corollary, if Foster had then prepared for that race seriously, the record would have been more difficult to break than it actually was). A runner can enhance the impression a time makes by invoking illness or injury, as when Rod Dixon tells us, "I was not $100 \%$ fit but I still went and ran 3:33.9" (Athletics Weekly, July 24, 1976). The assumption that the runner's time represented a maximum effort on his or her part can also be challenged, and a runner can draw on lack of effort as a resource to bring about a revaluation of time. Thus the same runner tells us:

I did a half-effort time trial on June 14th. I went for an hour's run in the morning, warmed up for about 30 minutes, went down to the track and started doing 66s. I ended up doing 13:54-half effort. (He ran 13:17.4 for 3rd in Stockholm on July 5th-Ed.). (Athletics Weekly, July 24, 1976)

Here both runner and editor collaborate to persuade us that we should not take the time, 13:54, as a true measure of Dixon's form. First we are told (twice) that it is a "half-effort" run. Then we learn that Dixon had run that day for one and a half hours before the time trial, so we may reasonably believe that he was at least a little tired. Next Dixon gives a casual impression about the whole thing ("I just went down to the track and started doing 66s"), and finally the editor tells us that less than three weeks later he ran a very fast time in a race, which provides confirmation, if confirmation were needed, that on June 14 it was indeed a "half-effort" run.

A note on the phenomenon of "splits" is essential to any consideration of the pragmatics of times. Splits are times taken for unit distances less than the whole distance being raced ("doing 66s" in the previous example). "Lap times" are the most common kind of split. They refer to the time taken for one lap, but splits can vary in length. The leader's splits for each mile or 5-kilometers stretch of marathon races are sometimes published, and splits for each 100 meters of major 1,500-meter world record races are becoming commonplace. Splits are objective indicators of the pace of a race. Before a race many runners will have knowledge of the splits that they 
will be aiming for. During a race, should they encounter actual splits that vary significantly from those projected, they may become disconsolate or fearful. Sometimes runners involved in very fast races do not wish to hear the splits, because "ignorance is bliss."

Just how crucial splits may be can be seen when a runner hears a split that is at variance with expectation. A common response is to find fault with either the timepiece or the timekeeping. A watch may not be believed to be working properly, or a timekeeper may be thought to have misread it:

I approached the group of waiting spectators, officials and timekeepers, striding well, listening for the lap time. "23:16." "23:16," I thought to myself, Christ, they're way out! I shouted back, "Christ Almighty, can't you read the bloody watch?" I was annoyed; I wanted to do a fast time, but I needed information that was accurate so that I could gauge my efforts.... Up to the slight incline to the markers at two laps I was keen to hear the proper time. "46:51." Christ they were right. This was really moving. I had two choices: slow down in case I blew up later, or keep it going. (Hill 1981:376)

Sometimes the fault is genuine. A distinguished field of middle distance runners was once defeated by its own "hare" (pacemaker). Afterward, several competitors explained that they had allowed the hare to build up such a big lead because the timekeeper had been calling out "fast" splits, which they thought were their own but which turned out to be the splits of the hare running some distance ahead of them. As a result of receiving this misinformation, their judgment of the pace was adversely affected.

Splits can serve yet another purpose for the evaluation of a time. Two identical times by different runners can be compared by analyzing their splits. The performance that diverges most widely from "even-paced" running is usually adjudged the most difficult to achieve. In marathon running at all levels, a premium is placed on the achievement of a "negative split," a second half of the race that is run faster than the first half. Thus these quantitative measures are not only of great interest to the statisticians of running performances. They enable runners themselves to make fine distinctions about the qualitative aspects of a particular time.

The ethnographic analysis of times may be regarded as empirically illustrating aspects of Mead's (1932) theory of temporality. In this analytic frame a "time" for a running performance is an emergent event, existing in a present and thus displaying the property of sociality, or "the capacity of being several things at once" (Mead 1932:49). The runner's physiological capabilities, resolve, tactical sense, and other personal qualities clearly define the performance, but it is not determined or foreordained by these qualities alone. Several environmental factors also inhibit or facilitate a runner's performance (terrain, weather, etc.). Thus a time, an apparently objective measure of performance, turns out to be an estimation shaped by the environment as well as the runner's athletic capacities. The accomplishment that the time represents is also social in Mead's sense, because it is determined by the runner's past training yet marks out a new vista of future performances that the accomplished 
time potentiates. For example, a runner completing a half marathon in eighty minutes will have confidence that appropriate training and preparation makes a marathon of under three hours within reach. In this respect, the present comes to have a malleable structure arising from the emergent character of a particular time.

In the preceding ethnographic analysis, I have emphasized two broad features of times. First, times can function as identity symbols, advertising a running capability and placing the runner in a clear location in the hierarchies of the running world as well as providing satisfactions felt appropriate to the accomplishment the time represents. Second, although a time is ostensibly an objective measure of duration, runners themselves subject it to close interpretive scrutiny, seeking to establish what it "really" means, what it is really "worth."

\section{CONCLUSION}

In these concluding remarks I want to consider my ethnographic analysis of running temporality in light of the critical theories with which I began. ${ }^{9}$ What implications does the ethnographic analysis hold for these critical approaches? And what might be the implications of such critical theories for the ethnographic analysis presented here?

It is easier to formulate a response to the first question than the second. Answers to both take us through some familiar argumentative terrain. Throughout this article I aimed to develop an ethnographic approach to the temporal patterning and symbolism of running informed by symbolic interactionism. The ethnographic dimension of my approach may be minimally defined by two ideas popularized by Clifford Geertz (1973, [1974] 1983): it seeks to develop a "thick description" of "the native's point of view." None of the critical theories reviewed earlier consider the runner's point of view as an important focus of analysis. This tendency is perhaps widespread in the sociology of sport (Kew 1986; Leonard and Schmitt 1987). Of course, it would be easy to place critical and ethnographic approaches in different boxes, acknowledging in the manner of Habermas (1972) that differing cognitive interests of emancipation and understanding animate them. However, if critical theories are allowed to breach this resolution for peaceful coexistence, they can readily misconstrue or caricature their chosen targets, ignoring or downgrading the rationalities of participants. ${ }^{10}$

From an interactionist, ethnographic perspective, critical theories present only partial, "thin" descriptions of the temporal aspects of running; the analyses they present rest on a questionable database. These theories trade on idealized, perhaps stereotypical conceptions of involvement in sport rather than treat the ethnographic description of the beliefs and practices that comprise involvement in sport as the essential basis of any thorough sociological analysis. In consequence, they neglect central concerns that this article has sought to document: the motivated character of training schedules, what sporting careers actually mean to participants (including the grounds for the appraisal of these careers), and how runners orient 
to and reason about "times" and "splits" as performance descriptors. My analysis suggests some of the deficiencies of theories based on thin ethnographic description and indicates an alternative approach that treats seriously the meanings of running to those who participate. Although a symbolic interactionist analysis of ethnographic and qualitative data cannot refute critical arguments, they can show what is lacking.

The tougher question concerns how critical theory might inform ethnographic analyses. Certainly runners sometimes experience training as onerous "work." They may adopt a systematic and calculative approach to planning, if not their entire running careers, at least what they hope to do over the next few months. They may become obsessed with times as measures of performances and performers. In these ways, running may on occasion resemble-and be experienced as-oppressive and exploitative work, racing against time that is always running away with us. (More often, however, runners' friends and intimates comment on their excessive absorption in the sport: acting like a cultural dope soon draws attention.)

As noted, critical theory's emancipatory impulse can serve as a reminder of alternative conceptions of running untainted by the temporal constraints characteristic of labor discipline in industrial capitalism. Whether runners need such a reminder remains open to question, because the critical impulse is not the sole prerogative of critical theory. It seems unlikely that runners unreflectively appropriate temporal forms, ideologies, and technologies from industrial capitalism. Runners themselves understand that it is important to run without wearing a watch and to just run according to how you feel, or that constantly monitoring times can be counterproductive. ${ }^{11}$ They understand that temporal organization can enable and constrain runners. It enables them by providing an accurate and reliable gauge of running performance, when interpreted appropriately. In addition, it permits them to schedule training that will make a race more comfortable to complete. It constrains them through imposing training schedules to follow and stopwatches that measure performance without negotiation. Runners recognize this temporal organization. It is part of the runner's self. That self is in part constituted by the kinds of temporal considerations outlined above. The cyclical racing pattern, the planned and scheduled character of training, the temporal dimensions of running careers, the vulnerabilities of times as performance descriptors-all provide a shared vocabulary and situated symbolism that runners know and appreciate in detail. This article has sought to examine some aspects of the temporal considerations that runners use that contribute to and reaffirm the runner's self. Rather than time oppressing and exploiting runners, runners exploit it as a constructive resource that they can deploy in diverse ways.

Acknowledgments: Earlier versions of this article were presented at the International Conference on the Future of Adult Life in Leeuwenhorst, the Netherlands, in July 1990 and in seminars at the Universities of Salford and Manchester, U.K. I am 
pleased to record my thanks to three anonymous reviewers for Symbolic Interaction and to Garry Crawford, Art Frank, Chris Loxley, Lee Monaghan, Ian Taylor, Rod Watson, and Doug Webster for their constructive comments. Thanks are especially due to Andrew Travers, who helped with both early and late versions of this article.

\section{NOTES}

1. I use the term "runners" to draw attention to the temporal practices of those who engage in distance running, though many of my observations apply to kindred athletic practices: sprinting, hurdling, steeplechasing, road running, cross-country, and race walking.

2. The standard format of the questionnaire profiles featured questions applied to nearly all respondents in the same order (see Appendix A). My use of the information is clearly guided by my sociologically oriented perceptions. The reality I have imposed on those answers is shaped by my focus on runners' temporal conceptions.

3. See Donnelly (1985:568), who makes a similar recommendation of the value of these sources for the study of sport subcultures.

4. In America, Baudrillard (1988) offers a famed and eloquent postmodern critique of running. Runners cannot be stopped, for their compulsive activity denotes a "mind riveted on the inner countdown to the moment when ... a higher plane of consciousness" is achieved (1988:37). But his claim that runners cannot be stopped because their minds are allegedly "riveted" on the achievement of "a higher plane of consciousness" overlooks both the general relevance in public places of the norm of civil inattention (Goffman 1963:83-88) and its temporary and conditional suspension in the case of runners exercising in public (Smith 1997:73, 76). Baudrillard's thin descriptions of that which he seeks to critique looks, from an interactionist point of view, to be little more than sarcasm posing as analysis. His description stands in contrast to the interactionist use of ironic tropes grounded in the close study of the worlds they describe (e.g., Goffman 1961; Hughes 1958).

5. Yet all too often these theories trade on an unreflective view of the relationship of macrosocial to microsocial processes, assuming that in the latter we can find simple reproductions or mirrors of the former. For an alternate view, see Goffman 1983.

6. Full-time runners, that is, those whose main source of income derives from the activity, are in a position to operate more flexibly in scheduling their long runs, because the temporal demands of paid employment do not affect them.

7. Some "committed" runners, for example, will run through injury or illness to "stick to" their chosen schedule, even if it entails risking longer-term damage to their health in the process. More "prudent" runners will build "slack" into their schedules, revise their goals, or seek alternatives. A sociological approach to running addiction might attend to such phenomena.

8. This response raises interesting questions about variations in how runners perceive time (Flaherty 1999) that interview methods might elicit in the immediate postrace or postrun situation.

9. A Weberian analysis may present a more parsimonious account than neo-Marxist and allied critical approaches to modern sport (see Guttmann 1978, 1981). In this view the pursuit of records, split-second timing, the drive toward quantification, and so on, in running is less a feature of capitalism than it is part and parcel of larger processes of rationalization characteristic of modernity as such. Moreover, the debates about the commodification of modern sport and its emancipatory potential clearly are far from settled (see, e.g., Digel 1988; Sewart 1987).

10. See Monaghan 2001 for an excellent examination of this tendency in sociological accounts of bodybuilding.

11. During an interview, a forty-year-old runner stated, "Because I am running slower now than at my peak, I've tended to stop looking at the stopwatches, because, although I feel fast, the times are depressing" (Runner's World, February 2002). 


\section{APPENDIX A \\ The Questionnaire Profile}

Full name?

Birthplace?

Date of birth?

Height?

Weight?

Pulse rate?

Which athletic club do you belong to?

Your occupation?

Your marital status?

Children?

Which town do you live in?

What hobbies and interests do you have outside athletics?

Who coaches you?

When and how did you become involved in athletics?

Which athletes do you admire?

What is your favorite event?

What are your personal bests?

When did you first realize that you could reach international level?

Where did you figure in major championships?

What is your annual progression for your main event(s)?

What has been your most pleasing performance?

What has been your greatest disappointment?

What is your target for next season?

What is your all-time goal?

What will you do after you retire from serious athletics?

What do you most like about athletics?

What do you most dislike about athletics?

What advice would you give to a youngster taking up athletics?

How often do you train?

For how long?

Where?

Is coaching important to you?

What kinds of training do you most like and dislike?

What training cycle do you follow?

Do you have a sample of a typical week's training in winter and in summer?

Do you rest before big competitions?

Will you make any changes to the pattern of your training in the future? 


\section{REFERENCES}

Athletics Weekly, July 24, 1976; January 22, 1977; November 2, 1977; December 24, 1979; April 19, 1980; May 3, 1980; May 19, 1980; May 30, 1980; August 23, 1980.

Baudrillard, Jean. 1988. America. London:Verso.

Berger, Peter L. and Thomas Luckmann. 1966. The Social Construction of Reality. London: Allen Lane.

Brohm, Jean-Marie. 1978. Sport: A Prison of Measured Time. Translated by I. Fraser. London: Ink Links.

Cottle, Thomas J. and Stephen L. Klineberg. 1974. The Present of Things Future: Explorations of Time in Human Experience. New York: Free Press.

Crossman, Jane, John Jamieson, and Linda Henderson. 1987. "Responses of Competitive Athletics to Lay-offs in Training: Exercise Addiction or Psychological Relief?" Journal of Sport Behavior 10(1):28-38.

Diekhoff, George M. 1984. "Running Amok: Injuries in Compulsive Runners." Journal of Sport Behavior 7(3):120-29.

Digel, Helmut. 1988. "The Prospects of Modern Competitive Sport." International Review for the Sociology of Sport 23(3):177-92.

Donnelly, Peter. 1985. "Sport Subcultures." Pp. 539-78 in Exercise and Sport Sciences Reviews 13, edited by R. Terjung. New York: Macmillan.

Durkheim, Emile. 1915. The Elementary Forms of the Religious Life. London:Allen \& Unwin.

Evans-Pritchard, E. E. 1939. "Nuer Time-reckoning." Africa 2(2):189-216.

- 1 1940, The Nuer: A Description of the Modes of Livelihood and Political Institutions of a Nilotic People. Oxford: Clarendon.

Finestone, Harold. [1957] 1964. "Cats, Kicks and Color." Pp. 281-97 in The Other Side, edited by H. S. Becker. New York: Free Press.

Flaherty, Michael G. 1999. A Watched Pot: How We Experience Time. New York: New York University Press.

Garfinkel, Harold. 1956. "Some Sociological Concepts and Methods for Psychiatrists." Psychiatric Research Reports of the American Psychiatric Association 8:181-95.

Geertz, Clifford. 1973. "Thick Description: Towards an Interpretive Theory of Culture.” Pp. 3-30 in The Interpretation of Cultures: Selected Essays. New York: Basic Books.

- [1974] 1983. "'From the Native's Point of View': On the Nature of Anthropological Understanding." Pp. 55-70 in Local Knowledge: Further Essays in Interpretive Anthropology. New York: Basic Books.

Goffman, Erving. 1961. Asylums: Essays on the Social Situation of Mental Patients and Other Inmates. New York: Anchor.

1963. Behavior in Public Places: Notes on the Social Organization of Gatherings. New York: Free Press.

1971. Relations in Public: Microstudies of the Public Order. London:Allen Lane.

—_ 1983. "The Interaction Order." American Sociological Review 48(1):1-17.

Guttmann, Allen. 1978. From Ritual to Record: The Nature of Modern Sport. New York: Columbia University Press.

. 1981. "Translator's Introduction." Pp. vii-xxxi in Bero Rigauer, Sport and Work. New York: Columbia University Press.

Habermas Jürgen. 1972. Knowledge and Human Interests. London:Heinemann.

Hill, Ron.1981. The Long Hard Road, Part One: Nearly to the Top. Hyde, Cheshire: Ron Hill Sports.

Hinkle, J. Scott, Bruce Lyons, and Kevin L. Burke. 1989. "Manifestation of Type A Behavior Patterning among Aerobic Runners." Journal of Sport Behavior 12(3):131-38.

Hughes, Everett C. 1958. Men and Their Work. New York: Free Press.

Inglis, Fred. 1977. The Name of the Game: Sport and Society. London:Heinemann.

Kew, Francis. 1986. "Playing the Game: An Ethnomethodological Perspective." International Review for the Sociology of Sport 21(4):305-22. 
L'Equipe. September 26,1977.

Leonard, Wilbert M., II and Raymond L. Schmitt. 1987. "The Meaning of Sport to the Subject." Journal of Sport Behavior 10(2):103-18.

Lyman, Stanford M. and Marvin B. Scott. 1968. "Accounts." American Sociological Review 33(6):46-62.

Marnham, Patrick. 1980. "Mind Control.” The Spectator July 26:25-26.

Mead, George Herbert. 1932. The Philosophy of the Present. La Salle, IL: Open Court.

Mills, C. Wright. 1940. "Situated Actions and Vocabularies of Motive." American Sociological Review 5:904-13.

Monaghan, Lee F. 2001. Bodybuilding, Drugs and Risk. London: Routledge.

Morgan, William J. 1978. "A Preliminary Discourse Concerning Sport and Time.” Journal of Sport Behavior 1(3):139-46.

Morgan, William P. 1979. "Negative Addiction in Runners." The Physician and Sports Medicine 7:57-70.

Nash, Jeffery E. 1976. "The Short and Long of It: Legitimizing Motives for Running.” Pp. 161-81 in Sociology: A Descriptive Approach, edited by J. E.Nash and J. P. Spradley. Chicago: Rand McNally.

. 1980. "Lying about Running: The Functions of Talk in a Scene." Oualitative Sociologv 3(2):83-99.

Opie, Iona and Peter Opie. 1973. The Oxford Book of Children's Verse. Oxford: Clarendon.

Peters, Roy. 1976. "Television Coverage of Sport." Stencilled Paper no. 48. Centre for Contemporary Cultural Studies, University of Birmingham.

Rigauer, Bero. 1981. Sport and Work. New York: Columbia University Press.

——. 2000. "Marxist Theories." Pp. 28-47 in Handbook of Sports Studies, edited by J. Coakley and E. Dunning. London: Sage.

Roth, Julius A. 1963. Timetables: Structuring the Passage of Time in Hospital Treatment and Other Careers. Indianapolis: Bobbs-Merrill.

Schutz, Alfred and Thomas Luckmann. 1974. The Structures of the Life-World. London: Heinemann.

Scott, Marvin B. 1968. The Racing Game. Chicago: Aldine.

Sewart, John J. 1987. "The Commodification of Sport," International Review for the Sociology of Sport 22(3):171-92.

Smith, Greg. 1997. "Incivil Attention and Everyday Intolerance: Vicissitudes of Exercising in Public Places." Perspectives on Social Problems 9:59-79.

Strauss, Anselm. [1959] 1977. Mirrors and Masks: The Search for Identity. London:Martin Robertson.

The Guardian. July 19, 1977.

Webb, Eugene, Donald T. Campbell, Richard D. Schwartz, and Lee Sechrest. 1966. Unobtrusive Measures: Non-reactive Research in the Social Sciences. Chicago: Rand McNally.

Wild, John. 1954. "The New Empiricism and Human Time.” Review of Metaphysics 4:537-57.

Zerubavel, Eviatar. 1977. "The French Republican Calendar: A Case Study in the Sociology of Time." American Sociological Review 42(6):868-77.

. 1981. Hidden Rhythms: Schedules and Calendars in Social Life. Chicago: University of Chicago Press. 